\title{
Challenges in Modeling the Effects of Trade Agreements on the Agricultural Sector
}

\author{
Patrick C. Westhoff, Jacinto F. Fabiosa, John C. Beghin, and William H. Meyers
}

Working Paper 04-WP 358

April 2004

\author{
Center for Agricultural and Rural Development \\ lowa State University \\ Ames, lowa 50011-1070 \\ www.card.iastate.edu
}

Patrick Westhoff is a research associate professor at the University of Missouri, Jacinto Fabiosa is a research scientist at lowa State University, John Beghin is a professor at lowa State University, and William Meyers is a professor at the University of Missouri. All four authors are affiliated with the Food and Agricultural Policy Research Institute.

This work was supported in part by USDA-CSREES grant 03-34149-13495. This paper was presented at the 2004 Southern Agricultural Economics Association Meetings, Tulsa, Oklahoma, February 17, 2004.

This publication is available online on the CARD website: www.card.iastate.edu. Permission is granted to reproduce this information with appropriate attribution to the authors and the Center for Agricultural and Rural Development, lowa State University, Ames, lowa 50011-1070.

For questions or comments about the contents of this paper, please contact Pat Westhoff, Research Associate Professor. University of Missouri-Columbia, 101 South Fifth Street, Columbia, MO 65201; Ph: 573-882-4647; Fax: 573-884-4688; E-mail: WesthoffP@missouri.edu.

The U.S. Department of Agriculture (USDA) prohibits discrimination in all its programs and activities on the basis of race, color, national origin, gender, religion, age, disability, political beliefs, sexual orientation, and marital or family status. (Not all prohibited bases apply to all programs.) Persons with disabilities who require alternative means for communication of program information (Braille, large print, audiotape, etc.) should contact USDA's TARGET Center at (202) 720-2600 (voice and TDD). To file a complaint of discrimination, write USDA, Director, Office of Civil Rights, Room 326-W, Whitten Building, 14th and Independence Avenue, SW, Washington, DC 20250-9410 or call (202) 720-5964 (voice and TDD). USDA is an equal opportunity provider and employer.

lowa State University does not discriminate on the basis of race, color, age, religion, national origin, sexual orientation, sex, marital status, disability, or status as a U.S. Vietnam Era Veteran. Any persons having inquiries concerning this may contact the Director of Equal Opportunity and Diversity, 1350 Beardshear Hall, 515-294-7612. 


\begin{abstract}
Major issues and challenges encountered in modeling and analyzing agricultural and trade policy reforms are reviewed. We focus on the modeling approach and pay special attention to the type and scope of the models, the calibration of a realistic baseline scenario, the representation of the reform agreement, the use of extra-model information, the choice of metrics to measure reform impacts, and emerging issues in policy modeling. Existing solutions and unresolved issues are examined. We stress the complementarity of various modeling approaches in assessing policy reforms and the importance of helping users understand the limitations of the chosen approach.
\end{abstract}

Keywords: agricultural policy, economic modeling, trade agreements.

JEL classification: Q17, Q18, F13 


\section{Challenges in Modeling the Effects of Trade Agreements on the Agricultural Sector}

Trade agreements pose unique challenges to the policy analyst. Simple partial equilibrium analysis may be adequate for estimating the directional impacts of a single change in tariffs or subsidies on trade, prices, production, and consumption. Trade agreements, however, typically result in a complex set of policy adjustments that have multiple, often contradictory impacts on commodity markets. Reforms frequently have important effects on non-agricultural sectors (e.g., energy, food processing, textiles, and apparel), with important feedback effects on agricultural markets. Competent analysts can disagree not just about the magnitude of likely agricultural market impacts but even about the direction.

Consider estimating impacts of a hypothetical new World Trade Organization (WTO) agreement for U.S. agricultural commodity markets. The hypothetical agreement would limit permissible agricultural tariffs, export subsidies, and internal support measures and would also change WTO rules in other areas. In evaluating such an agreement, the analyst is required to make a series of important choices which will eventually dictate the modeling approach to be used.

Some of the key choices and questions analysts must address are as follows:

- Types and scope of models. No single model can fully capture all the possible impacts of a complex trade agreement. Analysts must balance the desire for a broad sectoral, commodity, policy, and country scope with the need for detailed coverage of particular markets and policies.

- Reference scenario. A proper measure of the impact of a trade agreement is to compare results under a baseline, or "business-as-usual," scenario without the agreement in place with results from a set of projections or simulations that include the policy reform scenarios. An agreement to reduce subsidies by 50 percent relative to those during a reference period may have little impact on 
commodity markets if current policies have already reduced projected subsidies by 60 percent. The reference scenario can reflect recent history or a baseline projection over some future time horizon.

- Representation of the policy reform agreement. Even the most complex models fail to capture all the nuances of current policies, and agreements can be implemented in various ways. Bound tariffs are not the same as applied tariffs and policies are generally not as simple as modelers assume. Often the analysis is undertaken before the modalities of the agreement are spelled out, and it can be difficult simply to find current data on policy parameters. Further, analysts and their models must recognize that governments typically try to find ways to implement agreements that minimize harm to influential groups.

- Extra-model information. No matter how good a model is, there are certain to be some important features of a trade agreement that are not captured fully or properly by the model. Problems may range from insufficient model detail to changes in agent behavior that may result under a new trade regime. Analysts must decide whether and how to introduce judgment and/or other extra-model information.

- Metrics for measuring the impact of reforms. To indicate the impact of policy reforms, most modelers report impacts on market prices and quantities, trade flows, farm returns, and government budgets. These metrics address the concerns of some stakeholders, such as farm interests and policymakers. Also important to other stakeholders (consumers, environmental groups, non-governmental development organizations, and various foreign stakeholders) are welfare measures of aggregate gains and of transfers among groups.

- Emerging issues. It is well known that as tariff barriers decline, non-tariff measures (NTMs) become more important. Except for quantitative restrictions, relatively little attention has been given to quantification of NTMs in agricultural and food product trade. Since NTMs are prevalent in food and agricultural trade and more likely to restrain trade as tariffs decline, it is increasingly important to assess their impact on trade. Another issue is the incorporation of food markets 
close to the consumer. Value is added from the farmgate to retail, and consumers face a variety of choices, which can change when borders open.

The balance of our paper examines and reviews these major issues and challenges encountered in modeling and analyzing multilateral agricultural trade policy reforms. In the following sections, we focus on multimarket, partial-equilibrium models used for outlook projections and policy analysis, such as those used by the Organization for Economic Cooperation and Development (OECD), the Food and Agricultural Policy Research Institute (FAPRI), and the U.S. Department of Agriculture (USDA). Where relevant, points will be illustrated by discussing choices faced by analysts with FAPRI in conducting analysis of trade agreements and other policy changes. We review existing solutions and unresolved issues and stress the complementarity of various modeling approaches in assessing policy reforms.

\section{Types and Scope of Models}

Trade agreements affect many markets simultaneously. A new WTO agreement on agriculture, for example, could affect tariffs and subsidies for a wide range of agricultural products in many countries. On this basis, once could argue for a model that covers many countries and commodities and pays close attention to cross-commodity effects. Such a model would recognize that a limitation on subsidies reducing wheat production in one country may end up affecting not just wheat markets in that country and around the world but also markets for competing grains, animal products, and more.

Trade agreements affect more than just agricultural markets. Reductions in manufacturing product tariffs and other features of agreements may have important effects on production, trade, and prices in other sectors of the economy. In the aggregate, these effects may be large enough to have significant impacts on employment, investment, and income levels in the general economy. Similarly, in countries where agriculture is a significant share of the total economy, changes in agricultural markets may have meaningful impacts on non-agricultural sectors. Computable general equilibrium (CGE) models that explicitly account for interactions between agricultural and non-agricultural sectors of the economy have an obvious advantage in assessing economywide trade agreements (Hertel 1997; Goldin and van der Mensbrugghe 1996). CGE models also 
account for bilateral trade flows and so are better suited to capture the implications of regional trade agreements than are non-spatial models.

Provisions of trade agreements often are phased in slowly, as governments seek to give market participants time to adjust to policy changes. Market participants change investment decisions in response to changed incentives. In many cases, it takes time for the full consequences of changes in investment to be reflected fully in the supply and demand for agricultural products (e.g., biological lags mean that it may take some time for changed incentives to be fully reflected in beef production levels). Also, trade agreements often tie changes in subsidies or tariffs to levels prevailing during some base period. On the basis of these factors, once could argue for using dynamic models to assess the effects of trade agreements.

Proper analysis of trade agreements would seem to require large-scale, dynamic, general equilibrium models. Indeed, some excellent analyses of trade agreements have been done with CGE models (Hertel 1997; The World Bank 2003). Such models are particularly valuable when agreements have major impacts on the non-agricultural sectors of the economy, or when agriculture is a large portion of the general economy (e.g., in many developing countries). Despite progress made with the Global Trade Analysis Project (GTAP) (Hertel 1997), major trade-offs remain. CGE models sacrifice commodity and policy detail important in examining agricultural trade agreements and often lag on policy and market information.

FAPRI and OECD have opted for multi-market, partial-equilibrium models that lack desirable general-equilibrium features but provide considerable and very current detail in representing markets and policies for selected countries and commodities. The lack of sectoral interactions in these models can be crudely remedied by incorporating exogenous information from CGE analysis, such as shifts in growth of gross domestic product induced by trade liberalization.

Commodity and policy detail is especially important in evaluating the effects on world dairy markets of the Uruguay Round Agreement on Agriculture (URAA). The agreement places separate limits on allowable levels of subsidized exports of cheese, butter, skim milk powder, and "other dairy products." These limits have had significant impacts on the European Union, the predominant user of export subsidies, but the im- 
pacts differ across the various dairy products. E.U. subsidized exports of cheese and other dairy products (mostly whole milk powder) regularly have been constrained by the URAA limits, but the cap on subsidized E.U. butter exports has never been binding.

To estimate the impacts of the export subsidy limitation on E.U. (and world) dairy markets, it is useful to have a model that includes explicit representations of each of the product markets. The interrelationships among these markets must be properly captured. For example, cheese production can increase only if there is either an increase in milk production or a reallocation of milk fat and protein away from other dairy products. In the European Union, milk production is largely determined by marketing quotas, so allocation of milk components to various products is essentially a zero-sum game. To properly capture all the consequences of the URAA or a future trade agreement for dairy markets, the model must capture not only these technical and economic relationships but also the finer points of E.U. dairy policy, ranging from marketing quotas to intervention buying and consumption subsidies (Binfield et al. 2001).

In the case of cheese, analysis is further complicated by product heterogeneity. The URAA export subsidy limit applies to total cheese exports, but the European Union exports a wide variety of cheeses, and export subsidies are only used for certain cheeses to certain destinations. It would in some ways be desirable to model each of the varieties of cheese separately, but this is impractical, both because the model would quickly become unmanageable and because the required data are simply unavailable. The heterogeneity of cheese and the lack of data force analysts to make a series of assumptions about the substitutability (in production or consumption) of various cheeses, normal relationships between prices, and so forth. These assumptions, in turn, largely drive estimates of the impacts on exports and prices of a given limitation on subsidized exports.

\section{Reference Scenario}

Sometimes analysts will argue that baselines are not important, because what matters (or at least, should matter) is the change from the baseline that results when an alternative scenario is implemented. While there may be times when this is true, the particular provisions of many trade agreements mean that baselines matter, and they often matter a lot. 
The U.S.-E.U. joint proposal made prior to the failed meeting in Cancun provides prime examples of the importance of baselines. The proposal would have required reductions in amber box support, though the percentage reduction was unspecified. However, because such reductions would be relative to a capped level that is loosely tied to support levels from the 1980s, the actual reductions relative to a 2003 current policy baseline would very likely be small or even zero. Further, the joint proposal set a limit ( 5 percent of domestic production value) on spending in a redefined blue box that would include U.S. countercyclical payments and certain E.U. payments. Given a 2003 current policy baseline, it was unclear whether the proposed limitation was likely to ever prove binding on actual government support measures in the United States and European Union.

Because the results of analysis are often baseline dependent, FAPRI devotes considerable time and resources each year to the development of baselines that reflect current market and policy information. A preliminary baseline is prepared in November, reviewed at a December conference, and revised in January to incorporate reviewer comments and other new information. The baseline reflects current government policies in the United States and other countries and those that have been formally decided for the future. The January 2004 FAPRI baseline incorporates not only the 2002 U.S. Farm Security and Rural Investment Act and the 2003 E.U. reforms of the Common Agricultural Policy but also the accession of 10 new member states to the European Union in May 2004.

Having a baseline that reflects current information is critical if an analyst is asked for a best estimate of the impacts of a proposed trade agreement or other change in policy. While FAPRI prepares a baseline once a year, there are times when it would be desirable to update baselines even more frequently, as an out-of-date baseline can result in misleading analysis when macro-economic and market conditions evolve rapidly.

A prime example of this is detailed by Orden, Paarlberg, and Roe (1999), who describe the political process that led to the 1996 farm bill. An important factor contributing to the political success of decoupled payments was a Congressional Budget Office baseline that appeared inconsistent with conventional wisdom in late 1995. The baseline, prepared before the 1995 run-up in grain prices, projected relatively high expenditures under a continuation of 1990 farm bill policies. As prices rose, it became clear that actual 
expenditures under 1990 farm bill policies would be very small, at least in 1996. Guaranteed decoupled payments appeared to reduce government expenditures relative to the baseline prepared in early 1995, even though it was widely understood that payments under the program would actually exceed those that would have occurred under previous legislation, at least in the short run. Ironically, the late 1995 conventional wisdom also proved incorrect, as prices fell sharply in 1997, resulting in pressure to supplement the payments guaranteed under the 1996 farm legislation.

Given the inherent uncertainty of agricultural markets and the baseline dependence of many analytical results, FAPRI has begun the process of shifting to a stochastic approach to policy analysis. For U.S. markets, a simplified version of the FAPRI modeling system is used to generate 500 alternative baselines that differ from one another in their assumptions about a variety of random supply and demand factors. Draws of these exogenous variables are made from correlated empirical distributions based on data from the last 20 years or so. The results generated allow one to examine a wide variety of possible outcomes for commodity markets and to examine the impacts of policy changes under different starting conditions.

The importance of this approach is clear in the case of many U.S. farm programs that have asymmetrical effects. For example, consider the marketing loan program. If demand is strong, market prices may be well in excess of loan rates and producers may make production decisions with little reference to potential loan program benefits. On the other hand, if demand is particularly weak, prices may be well below loan rates and the resulting marketing loan expenditures may be large. At low market prices, the marketing loan program may have large impacts on producer planting decisions. Because marketing loan benefits cannot be negative, the mean results from 500 alternative futures are often significantly different from results generated under the single deterministic baseline. In three years of doing this type of analysis, FAPRI has found that, due to these asymmetric payment effects, average levels of government spending in the stochastic baseline are consistently larger than are levels of government spending in the deterministic baseline.

Time and resource constraints have not allowed FAPRI to extend the stochastic approach to its models for other countries, so FAPRI has not conducted an assessment of a 
multilateral trade agreement using stochastic analysis. Given asymmetries in government policies and interest in how alternative trade rules might play out under different market conditions, there are reasons to extend the use of stochastic methods.

\section{Representation of the Policy Reform Agreement}

The dairy example points out the importance of ensuring that the terms of a trade agreement being negotiated are properly reflected in the model. Only a very detailed model can explicitly incorporate both current policies and the combination of policy changes that is likely to result from a trade agreement.

\section{Market Access}

Tariff reductions illustrate the complex reality of current policies. The provisions of trade agreements make analysis much more complicated than in the textbook case. Often cited are the tariff overhang, the distinction between bound and applied tariffs, and "water in the tariff," the redundant tariff problem (de Gorter, Ingco, and Ignacio 2004). One can cite numerous examples in which current bound tariffs are well above applied tariffs, so that even a large reduction in bound tariffs may have little or no impact on the tariffs actually paid by importers and, thus, little impact on commodity markets. In response to the URAA, countries showed great creativity during the tariffication process in selecting base periods, reference prices, transportation costs, and quality differentials.

Similar pitfalls may take place with most-favored nation and preferential tariffs, when increasing quantities are being traded under preferential agreements. In spite of recent efforts, getting reliable, current data on applied tariffs remains difficult, as illustrated by the World Integrated Trade Solution (WITS) database managed by the World Bank and the United Nations Conference on Trade and Development, so modelers are often tempted to treat bound and applied tariffs as if they were synonymous. Making such an assumption introduces a systematic and potentially large bias in quantitative analysis. Data on preferential tariffs are even less well covered in many databases. Having current information is also critical. The lagged information in the GTAP database, for example, often overstates protection because it does not reflect current WTO commitments; hence, policy simulations based on GTAP protection data will exaggerate resource allocation effects and welfare implications of multilateral tariff reforms. ${ }^{1}$ 
The difficulty in properly capturing the impacts of tariff reduction goes far beyond concerns about the distinction between applied and bound tariffs. A nontrivial issue is that supply, demand, and trade data are often reported in terms of aggregated commodities (e.g., cheese), rather than the products corresponding to multiple tariff lines in each country's tariff code. Even where data are available, aggregation raises a host of problems on how to aggregate meaningfully the tariff lines. This problem pervades all modeling approaches to some degree.

Tariff rate quotas (TRQs) likewise raise a variety of thorny issues, as reality is often much more complicated than are textbook examples. Even an underfilled TRQ may have important market impacts, depending on the reasons for the underfill. Where TRQs are binding, market prices in exporting and importing countries may be largely divorced from one another, making it difficult to determine a "normal" basis between prices in the two countries (de Gorter and Hranaiova 2004; Skully 2001).

Finally, agreements like the URAA often do not prescribe in advance the precise levels of permissible tariffs on a commodity-by-commodity basis. The broad agreement may require an average rate of reduction across all tariff lines, as did the URAA, with commodity-specific reductions only spelled out in country schedules that are often unavailable when analysis must be done. Analysts, therefore, often must make their own assumptions about how a general tariff-reduction rule will actually be implemented. While it is convenient to assume that all tariff lines will be treated equally, it is generally safe to assume that countries will use whatever discretion they have to minimize harm to influential groups.

A host of other areas are intentionally left vague, allowing for strategic choices by policymakers. For example, in reference to the Doha modalities, one can think of the set of special products developing countries can claim for food security, rural development, and livelihood security concerns. These products are given differential treatment. Further, different TRQ expansion rates can be assigned to different products, provided that a quarter of the TRQ with lower expansion rates is balanced with a similar number at a higher expansion rate. Finally, countries with export subsidy commitments can select which products will be phased out in the longer or shorter terms. 
It is commonly accepted that the reality of tariff reduction under the URAA had far smaller market impacts than anticipated during the negotiations. Many analysts (e.g., Goldin and Knudsen 1990; Helmar, Meyers, and Hayes 1994) probably overestimated effects of the agreement's market access provisions (Meilke, McClatchy, and de Gorter 1996). Model shortcomings related to bound versus applied tariffs, heterogeneous products, and the like account for some of the overestimation, but much of it stemmed from a failure to capture the lengths to which countries would go to exploit provisions of the agreement to protect sensitive markets. Tariffication (the process of converting import quotas and other quantitative restrictions into TRQ equivalents) often resulted in little or no real additional access, as countries "creatively" used the new rules to set out-of-quota tariffs at such high levels that they remained prohibitive even after mandated reductions. TRQs themselves were often set at levels well below those assumed by modelers, who took the proclaimed targets (e.g., minimum access equal to no less than 5 percent of domestic consumption) too literally.

\section{Internal Support}

In spite of all the problems associated with modeling tariffs and other market access measures, the problems are probably much greater in the area of internal support measures. One could argue that the final URAA did little to reduce the total level of government support provided agricultural producers in the United States, European Union, and most other countries. In part, this was because the negotiators were clever in writing the final provisions in such a way that most policies in place in 1994 could have been retained indefinitely without running afoul of the agreement. Perhaps the most important effect of the internal support agreement was not to encourage countries to reduce overall levels of payments to producers and land owners but to move support from categories subject to limitation to categories not subject to limitation.

Models without detailed representation of government price and income support policies are ill-equipped to examine the implications of an agreement like the URAA. For a given level of government support as measured by a producer support estimate or an aggregate measure of support, different policies may have very different implications for commodity supply. 
Especially important are decisions about how to represent the impacts of payment programs that are fully or at least partially decoupled from production decisions. While most analysts would agree that a dollar spent on U.S. marketing loan benefits would have a different impact on production than a dollar spent on direct or countercyclical payments, there is little agreement on just what the impacts would be. If the United States were to respond to requirements of a new trade agreement by increasing less coupled support (e.g., direct payments) to offset reductions in more coupled support (e.g., marketing loan benefits), the estimated net effect on commodity supplies would obviously depend on how these policies are modeled.

Finally, it should be noted that good estimates of the effects of policies on crop supply are only possible if models properly handle cross-commodity effects. In FAPRI's U.S. crops model, the acreage devoted to any given crop is fairly sensitive to relative returns from the market and coupled payment programs. However, the total cropland devoted to production of the major field crops in aggregate is relatively inelastic with respect to returns. (In the current version of the model, the aggregate elasticity of major field crop area with respect to weighted-average net returns over variable production costs is 0.06.) As a result, even a fairly large change in coupled payments will have only a modest effect on overall crop area, although it may have a major impact on the mix of crops produced.

\section{Extra-Model Information}

By their nature, trade agreements often require significant changes in policies that fundamentally change the decisions faced by economic agents. As a result, model parameters estimated from time-series data often may have limited relevance. Even when the basic structure of agent decision making is not altered, major policy reforms can result in decision variables that take values far out of the range of the historical data. A variety of other factors may also make it unreasonable to expect time-series data to provide all the information needed to build models appropriate for policy analysis (Just 2001).

Practitioners of policy modeling know that models are in a constant state of repair. New out-of-sample data may suggest that old equations are inadequate, or a fundamental change in policy or structure may mean that underlying model assumptions no longer 
hold. In some cases, a better model can be created through standard techniquesrespecifying and re-estimating equations, and so forth.

Price expectations are important in modeling both supply and demand behavior. Models that assume naïve or adaptive expectations may perform adequately under most circumstances but may fail to capture the consequences of policy changes that alter agent expectations. In some cases, one possible response is to incorporate contemporaneous prices in supply response functions (e.g., Sumner and Wohlgenant 1985; Hertel 1997; Beghin et al. 2003).

In many other cases there is simply no practical way to improve the model using standard statistical techniques. Data may be unavailable or unreliable, or the new situation may be so novel that available data are of little value. In addition, the reality is that important policy analysis must often be done quickly, before there is time to fully rework models so they are ideally suited to the question at hand. In these circumstances it is both necessary and desirable to incorporate as much extra-model information as possible.

FAPRI places a lot of emphasis on collecting and incorporating extra-model information whenever necessary and appropriate. The baseline review session each year is a formal means of identifying factors that may not be properly incorporated in the model. When time and resources permit, the information obtained is used to suggest changes in the model. Estimated equations may be re-estimated, and the parameters in synthetic equations may be altered. In other cases, the new information may simply be incorporated by means of calibration factors added to existing model equations.

In all cases, the goal is to develop a set of projections that reflects the analyst's best judgment about likely market outcomes under the stated set of assumptions. The model is used as a tool to ensure that results are consistent with biological and economic fundamentals, but essentially the estimates are those of the analysts, not of the model. As argued by Just, this approach is not only acceptable, but it is essential for those who wish to provide the best possible information about the likely impacts of policy change.

\section{Metrics for Measuring the Impact of Reforms}

Economists, by training, care about efficient allocation of resources or net social welfare. However, agricultural producers and policymakers may care less about net social 
welfare than about the effects of policy changes on prices, production, trade, producer returns, and budgetary expenditures. Hence, transfers are often more informative than is the net efficiency impact. A recurrent observation is that consumers are often ignored in the analysis, although they may bear the brunt of farm and trade policy. When consumer interest is involved or when society at large cares about policy impacts, existing projection models can easily be extended using approximations of welfare effects with Marshallian surplus measures and transfers. The models can also be retrofitted on demand to compute "exact" welfare measures using flexible approaches satisfying integrability $^{2}$ (Beghin et al. 2003).

The computation of the budgetary implications of policy reform has become more complex with the increasing presence of countercyclical policies that may or may not be effective depending on the state of the world. One can use stochastic analysis in the evaluation of policy options when such considerations are needed. For example, a deterministic analysis may suggest that current U.S. policies would comply with WTO limitations on internal support measures (Hart and Babcock 2002), but stochastic analysis may reveal a significant probability that subsidy limits would be breached in the absence of policy changes (FAPRI 2002). In other words, the expected value of estimated impacts from stochastic analysis may be significant even when the estimated impact from deterministic analysis is zero. For many issues, a deterministic analysis may give significantly different results than would a stochastic analysis that reflects the inherent uncertainties in world commodity markets.

\section{Emerging Issues}

\section{Non-tariff Measures}

It is well known that as tariff barriers decline, NTMs become more important. Such measures can be broadly defined (Deardorff and Stern 1998) as measures that lead to a reduction in import quantity, increase prices of imported goods, change the elasticity of demand for imports, diminish price transmission, increase uncertainty, or by other means add non-market costs to transaction costs of traded goods. Some of these measures are as visible as quantity and price restrictions and sanitary and phytosanitary regulations, and some are as invisible as customs delays and corruption. These measures can be imposed 
at the border or in domestic markets. NTMs include export as well as import restraints, though emphasis tends to be on the import restraint side. Some of these measures are

disciplined by WTO and GATT agreements, some are allowed and not disciplined, and some are not allowed.

Examples of NTMs include price controls (floor and ceiling prices, variable levies), quantitative controls (import licensing, quotas, import bans, export restrictions), state trading enterprises (sole importing and exporting agencies), technical trade barriers (standards, labeling, certification, testing), customs (classification and clearance), subsidies (production and export), and intellectual property rights (protection level, discriminatory protection).

To better assess the benefits of the trade liberalization in agriculture, we have to be able to assess how the reduction in NTMs will increase market access in agriculture. A recent analysis shows that for both developed and developing country exporters, "... agricultural products are the sector with the highest incidence of NTMs" (Bora, Kuwahara, and Laird 2002). Since NTMs are so prevalent in food and agricultural trade and more likely to restrain trade as tariffs decline, it is increasingly important to assess their impact on trade. Except for quantitative restrictions, relatively little attention has been given to quantification of NTMs in agricultural and food product trade. In the context of trade liberalization studies, NTMs would generally diminish the benefits of liberalization and it is important to know whether this diminution is large or small. It is important to attract more attention to this issue, to learn from the more extensive work that has been done (including in other product categories), and, hopefully, to stimulate innovations that will improve our analysis (Beghin and Bureau 2001).

There are also new NTMs arising from opportunistic behavior in TRQ administration leading to trade impediments and quota underfill. It is difficult to capture in any model the impact of these various administrative mechanisms used by countries in implementing the allocation of TRQs (Skully 2001). The dispute between the United States and the Philippines on pork is a classic example.

\section{Value-Added Products}

Partial equilibrium models tend to focus on agricultural raw materials; they overlook or ignore much of the value added beyond basic processing. The typical models include 
oil and meal from processed oilseeds, meat from live animals, dairy products from milk, and raw sugar from sugar beets and cane. However, much value is added in further processing and then in retailing. The models do not reflect the true choice set for consumers. Because the coverage of value-added products is wanting in these models, analysts are not able to capture the impacts of tariff escalation and proposals to reduce the escalation, as suggested in the Doha modalities.

Britz and Schmidhuber (2002) provide a first attempt to incorporate retail margins into consumer prices in the FAPRI-type model used for the Food and Agriculture Organization's long-term projections. Their model exhibits higher consumer prices in industrialized countries to reflect the higher post-farmgate value added common in more advanced countries. However, the model treats the commodities in different countries as being homogeneous and connected to a single world market, although they embody heterogeneous value-added attributes across countries.

Further, most projection models do not reflect the increase in the choice set brought by trade liberalization. When borders open, new products compete with domestic products. Trade liberalization brings gains in efficiency and increased product quality and diversity in protected domestic industries facing increased competition. For example, following NAFTA, Mexican consumers had a better choice of dairy products, and domestic brands dramatically improved their quality and expanded their line of products. As a result, Mexican consumers were better off and productivity in the Mexican dairy sector has increased substantially. Most models typically underestimate these gains from the expanded set and from the increased quality of domestic products, unless a StiglitzDixit-Spense structure is specified (Dixit and Norman 1980). This kind of consumer approach is ill-suited for FAPRI-type models that assume markets with homogenous commodities. $^{3}$

\section{Concluding Comments}

Analysts face many challenges in modeling and analyzing agricultural and trade policy reforms. We focused on modeling approaches and paid special attention to the types and scope of models, the calibration of a realistic baseline scenario, the representation of the future reform agreement, extra-model information required for the analysis, the 
choice of metrics to measure the impact of policy reform scenarios, and new issues facing policy modelers.

Because of the many ambiguities regarding implementation of trade agreements, analysts are compelled to make certain assumptions about how countries will convert the terms of a trade agreement into actual policy changes. Any given interpretation is just one possibility in a continuum of possible cases. This uncertainty often leads analysts to examine limited cases such as full-liberalization scenarios.

No single modeling approach dominates the others on all fronts, and some are better than others at specific tasks. The importance of complementary approaches cannot be overstated. CGE models have their own shortcomings but they force conceptual consistency on a problem (Goldin and van der Mensbrugghe 1996) and provide useful information on spatial trade flows and factor prices important to agriculture (Hertel 1997). They also capture feedback effects between processing sectors and agriculture that can be at best mimicked in partial equilibrium models. Muth-type multimarket models (Sumner and Wohlgenant 1985) provide useful insights because they include instant supply responses often lacking in large projection models; provide detailed welfare analysis, including transfers among agents; and are useful as learning devices to trace policy impacts on various agents and markets.

Projection multimarket models such as OECD's AGLINK model, the FAPRI model, and USDA's commodity models have their own sets of strengths and weaknesses. Analysts using these models typically place a high premium on developing realistic baseline projections. Because estimates of the impacts of trade agreements and other policy changes are often very baseline dependent, it can be critical to have a baseline consistent with the latest available information on markets and policies. These models often carry more detail on particular policies and how they impact agent behavior than is found in other models. On the other hand, these models are often weak in terms of dynamics, price expectations, and linkages to the rest of the economy.

In policy analysis, ignorance is not bliss! This is seemingly pedestrian but important and relevant to the policy analyst. Even the best models are dangerous tools in inexperienced hands. Often a novice modeler does not perceive the limitations of the chosen tool and approach and just "cranks" the model without understanding the forces at work or 
even the economics implied by model specification. This is true for all approaches. The more ready-to-use the modeling tool, the more dangerous the novice analyst tends to be. We would argue that the largest models such as GTAP are more exposed to this risk because of the user-friendliness and the large coverage of products and countries. Credible policy analysis relies on a combination of market intelligence, specialized knowledge, and modeling expertise. 


\section{Endnotes}

1. The GTAP 5 database relies on 1997 and older data. The forthcoming GTAP 6 relies on 2000 and older data but it is still being debugged. However, comparing the newer and older data suggests that protection has been overstated by GTAP 5.

2. Integrability refers to the existence of well-defined preferences underlying a system of consumer demand that allow recovery of a well-behaved expenditure function rationalizing the consumer demands and leading to a consistent utility function.

Integrability implies that Hicksian demands have a symmetric, negative, semi-definite substitution matrix.

3. The increased efficiency could be mimicked by incorporating exogenous changes in productivity resulting from the policy shock, but this is a fix rather than an elegant solution. 


\section{References}

Beghin, J., and J-C. Bureau. 2001 "Quantitative Policy Analysis of Sanitary, Phytosanitary and Technical Barriers to Trade." Economie Internationale 87: 107-30.

Beghin, J., B. El Osta, J. Cherlow, and S. Mohanty. 2003. "The Cost of the U.S. Sugar Program Revisited." Contemporary Economic Policy 21(1): 106-16. Reprinted in International Sugar Journal 105: 293-303.

Binfield, J., T. Donnellan, K. Hanrahan, and P. Westhoff. 2001. "The Impact of WTO Export Subsidy Reductions on Agricultural Output, Prices, and Farm Income in Ireland." In FAPRI-Ireland Outlook 2001: Medium-Term Analysis for the Agri-Food Sector. Dublin: Teagasc, April, pp. 80-103.

Bora, B., A. Kuwahara, and S. Laird. 2002. "Quantification of Non-tariff Measures." Geneva: United Nations Conference on Trade and Development (UNCTAD) Policy Issues in International Trade and Commodities, Study Series N. 18.

Britz, W., and J. Schmidhuber. 2002. “2030: A First Step Towards a Modelling System for FAO's LongTerm Projections for World Agriculture.” In Liberalisierung des Weltagrarhandels- Strategien und Konsequenzen, Band 37. Schriften der Gesellschaft für Wirtschafts- und Sozialwissenschaften des Landbaus e.V., Edited by M.F. Brockmeier, F. Isermeyer., and S. von Cramon-Taubadel, MünsterHiltrup: Landwirtschaftsverlag, Germany.

Deardorff, A.V., and R.M. Stern. 1998. Measurement of Nontariff Barriers: Studies in International Economics. Ann Arbor: University of Michigan Press.

de Gorter, H., and J. Hranaiova. 2004. "Quota Administration Methods: Economics and Effects With Trade Liberalization." In Agriculture and the WTO: Creating a Trade System for Development. Edited by M. Ingco, and J.D. Nash. Washington, DC: World Bank Publications.

de Gorter, H., M. Ingco, and L. Ignacio. 2004. "Market Access: Economics and the Effects of Policy Instruments." In Agriculture and the WTO: Creating a Trade System for Development. Edited by M. Ingco, and J.D. Nash. Washington, DC: World Bank Publications.

Dixit, A.K., and V. Norman. 1980. "Scale Economies and Imperfect Competition." In The Theory of International Trade. New York: Cambridge University Press.

Food and Agriculture Policy Research Institute (FAPRI). 2002. "The House and Senate Farm Bills: A Comparative Study." Policy Working Paper \#01-02, FAPRI, University of Missouri, Columbia, and Iowa State University, Ames.

Goldin, I., and O. Knudsen, eds. 1990. Agricultural Trade Liberalization: Implications for Developing Countries. Paris: Organisation for Economic Co-operation and Development, and Washington, DC: The World Bank.

Goldin, I., and D. van der Mensbrugghe. 1996. "Agricultural Tariffication under the Uruguay Round.” In The Uruguay Round and the Developing Countries. Edited by W. Martin, and L.A. Winters. Cambridge: Cambridge University Press. 
Hart, C.A., and B.A. Babcock. 2002. "U.S. Farm Policy and the WTO: How Do They Match Up?" Estey Centre Journal of International Law and Trade Policy 3: 119-39.

Helmar, M.D., W.H. Meyers, and D.J. Hayes. 1994. "GATT and CAP Reform: Different, Similar, or Redundant?" In Agricultural Trade Conflicts and GATT. Edited by V. Anania, C.A. Carter, and A.F. McCalla. Boulder, CO: Westview Press.

Hertel, T.W., ed. 1997. Global Trade Analysis: Modeling and Applications. Cambridge: Cambridge University Press.

Just, R.E. 2001. “Addressing the Changing Nature of Uncertainty in Agriculture.” American Journal of Agricultural Economics 83(5): 1131-53.

Meilke, K.D., D. McClatchy, and H. de Gorter. 1996. "Challenges in Quantitative Economic Analysis in Support of Multilateral Trade Negotiations.” Agricultural Economics 14(3): 185-200.

Orden, D., R. Paarlberg, and T. Roe. 1999. Policy Reform in American Agriculture: Analysis and Prognosis. Chicago: University of Chicago Press.

Skully, D.W. 2001. "Economics of Tariff-Rate Quota Administration." Washington, DC: U.S. Department of Agriculture, Economic Research Service Technical Bulletin No. 1893.

Sumner, D.A., and M.K. Wohlgenant. 1985. "Effects of an Increase in the Federal Excise Tax on Cigarettes." American Journal of Agricultural Economics 67(2): 235-42.

The World Bank. 2003. "Global Economic Prospects 2004." In Realizing the Development Promise of the Doha Agenda. Washington, DC: The World Bank. 